\title{
Hemangiolymphangioma of buccal cheek- a rare case report with review of literature
}

\begin{abstract}
Vascular anomalies are divided in two Groups-Hemangiomas and Vascular malformation. Hemangioma and Lymphangioma are both examples of vascular tumours. Hemangiomas are proliferative vascular lesions present since birth While Lymphangiomas are hamartomatous tumours of lymphatic vessels. Sometimes pathologically, lymphatic channels may be seen in hemangioma thus, categorising them based on predominant component in Hemangiolymphangioma or Lymphangiohemangioma. In this present article, we have presented a case report of 5-year-old child with haemangiolymphangioma of buccal cheek with review of all cases in oral cavity reported in the literature. We have also enumerated various treatment modalities.
\end{abstract}

Keywords: hemangiolymphangioma, hemangioma, lymphangioma, oral cavity, vascular anomalies
Volume II Issue 5 - 2020

\author{
Divyachampa DN Khaunte, Praveen S Kumar, \\ Vikas Dhupar, Mohan Naik \\ Department of Oral \& Maxillofacial Surgery, Goa Dental \\ College \& Hospital, India
}

Correspondence: Divyachampa DN Khaunte, Senior Resident, Department of Oral \& Maxillofacial Surgery Goa Dental College \& Hospital, Goa India, Email divyakhante@gmail.com

Received: September 02, 2020 | Published: October 12, 2020
Abbreviations: HLA, hemangiolymphangioma; LHA, lympahngiohemangioma; PK, plasma knife

\section{Introduction}

Anomalies of vascular nature are congenital errors in Vasculogenesis. Based on their cellular features they are classified into two main categories: Hemangioma and Vascular Malformations. Hemangiomas are the most common vascular lesions in infancy with increased mitotic activity. They usually appear in late fetal/early neonatal life and regress spontaneously before/during puberty with two phases primarily, proliferative \& involuntary phase. Majority of Hemangiomas occur in head and neck region but rarely seen in oral cavity. ${ }^{1}$

Malformations are structural anomalies of blood vessels present since birth that fail to regress as the child grows and are with normal mitotic activity. They may have combination of arterial, venous, capillaries \& lymphatic component with or without fistulae. Based on diameter of vessels they are further classified in capillary, cavernous, arterio-venous, \& lymphatic.

Lymphangiomas are abnormality of lymphatic system, which are developed from sequestration of the primitive lymphatic cells. These vessels are capable of accumulating fluids and do not anastomose with bigger lymphatic vessels leading to lymphatic blockage. This is responsible for cystic appearance of lymphangioma. About 50\% of lymphangiomas are diagnosed in infancy while $90 \%$ are developed in early childhood as lobular masses or cystic lesions. ${ }^{2}$ Most common sites are head and neck; however, it is rarely reported in oral cavity. In oral cavity, it is mostly seen on tongue while many lesions have also been reported on palate, gingiva, lips \& alveolar ridge of mandible.

The term Hemangiolymphoma (HLA) or Lymphangiohemangioma (LHA) are lymphangiomas/hemangioma with a vascular or lymphatic component. Although histologically, it is a benign vascular lesion which is in fact rare and has potential for growth by cell proliferation. They consist of localized centres of abnormal development of the lympho-vascular system. It has inclination for rapid growth and invasion into the adjacent tissues with ability to recur locally. It can occur in multiple anatomical areas like head \& neck, axilla, abdominal cavity, extremities and urinary bladder. According to literature, 40 $60 \%$ of HLA are discovered at birth, $80-90 \%$ during the first 2 years of life, and decreases in frequency with age. ${ }^{3}$

The risk of developing HLA is greater in premature babies and in live new-born's incidence of 1:12 000 is noticed. ${ }^{4}$ Here we are presenting a case report of 5-year-old child diagnosed as HLA of buccal cheek.

\section{Case}

A 5-year-old male child accompanied by parent reported to our out-patient department with history of swelling on right side of face for 2 months. The parents noticed a sudden increase in the size of swelling since last 1.5 weeks. The swelling was not associated with any odontogenic cause or infection. The child was otherwise healthy with no other medical/family history.

On Inspection, the swelling was noted over right cheek, extending supero-inferiorly to a line joining from earlobe \& commissure of mouth and antero- posteriorly extending approximately $3 \mathrm{~cm}$ posterior to commissure up to the angle of mandible (Figure 1). On palpation, swelling was soft, fluctuant, non-tender, compressible but not reducible. It was not fixed to underlying bone. Right side submandibular lymph node was palpable but was mobile and nontender. On Intra-oral examination revealed mild bluish hue under the mucosa. No obliteration of buccal vestibule was noted (Figure 2). The Stenson's duct was patent and on milking showed normal flow of saliva.

Ultrasonography and doppler study of cheek revealed multiloculated cystic lesion with no vascular fill, most likely representing a lymphangioma. Following which patient was advised CT scan which revealed well defined mass measuring $3.6 \times 1.3 \times 3.7 \mathrm{cms}$ (APxTRxSI) in size on right cheek showing minimal enhancement on post contrast scan. Posteriorly, it was seen to overlie on masseter muscle with loss of intervening fat planes. Laterally, the mass was seen to extend into subcutaneous fat. Medially, the mass was contiguous with the buccinator muscle with loss of intervening fat plane. Inferiorly, it was 
seen to lie in close proximity to ramus of mandible (Figure 3). The facial artery was seen to course along the inferior aspect of the mass. There were multiple sub-centimetric lymph nodes noted in submental, submandibular and along the jugular chains on both sides. Surgical excision of the lesion was planned under general anaesthesia.

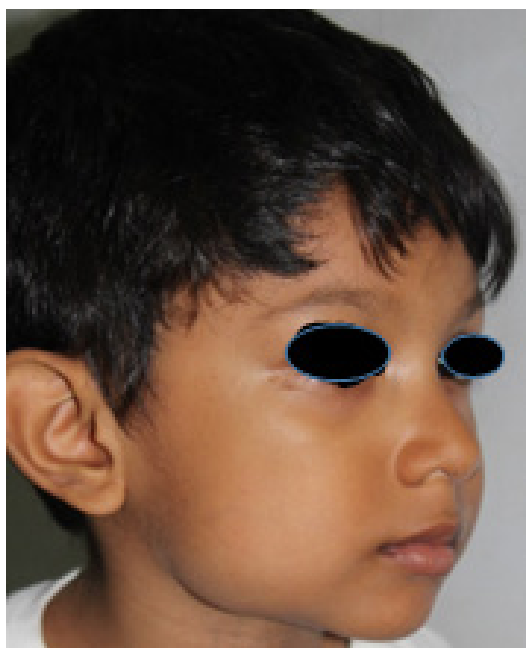

Figure I Angle of mandible.

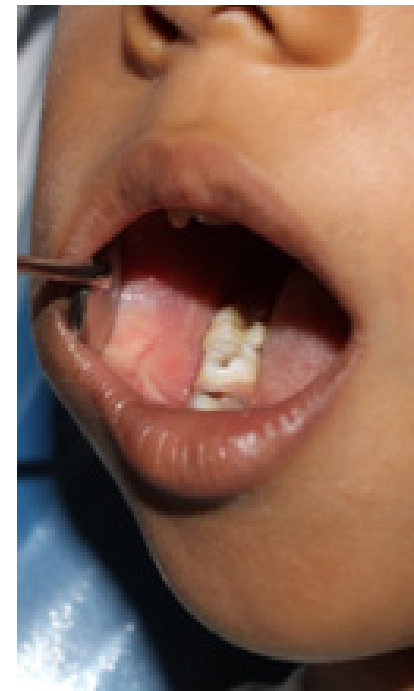

Figure 2 Buccal vestibule.

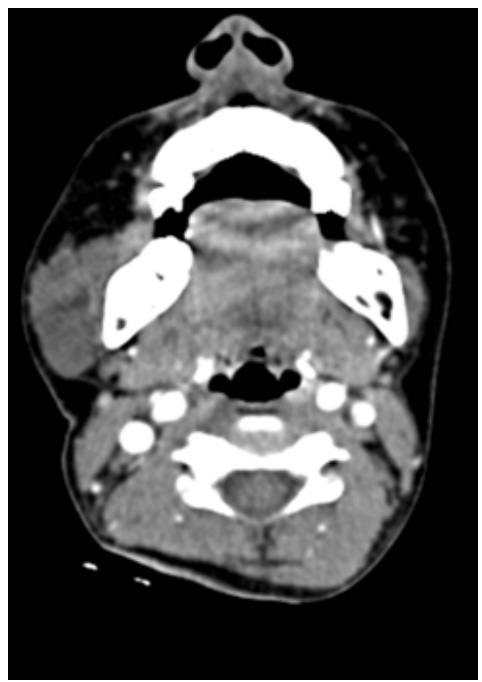

Figure 3 Post contrast scan.
A horizontal intra-oral incision was used to approach the lesion after careful identification of the Stensons duct. The dissection was carried through the buccinator muscle and the lesion was excised. The incision was closed using 3-0 vicryl sutures (Figures 4 \& 5).

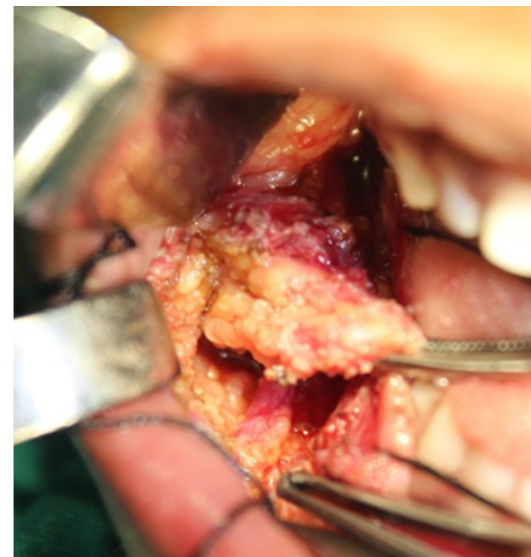

Figure 4 Multiple sub-centimetric lymph nodes were noted.

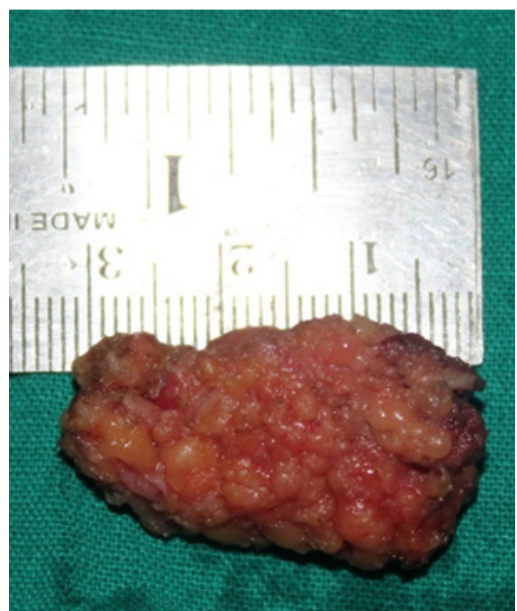

Figure 5 The incision was closed using .3-0 vicryl sutures.

On histopathology, H\& E stained sections showed multiple large irregular cystic luminal spaces supported by a fibro-vascular connective tissue capsule. The cystic luminal spaces were empty and lined by a single layer of endothelial cells. The connective tissue capsule showed collagen fibres, fibroblast, large number of engorged blood vessels, focal area of myxoid change and foci of dense chronic inflammatory cell infiltrate chiefly consisting of lymphocytes suggestive of HLA of cheek. Patient is on regular follow-up \& no recurrence has been noted till date (Figure 6).

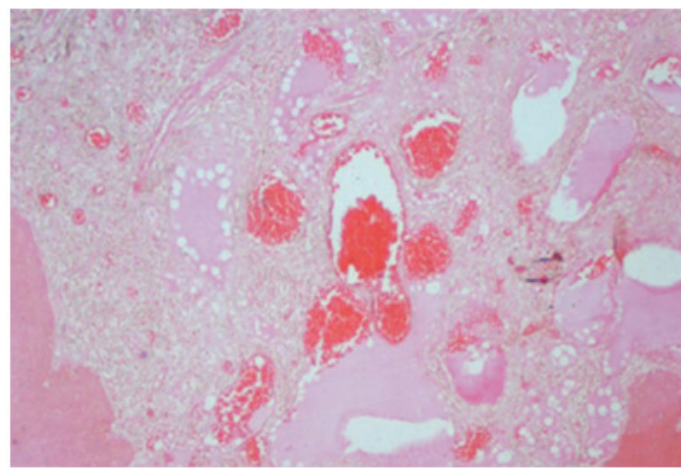

Figure 6 The cystic luminal spaces were empty and lined by a single layer of endothelial cells. 


\section{Discussion}

Vascular malformations are characterized as either high-flow (arterial components) or low-flow (venous and lymphatic components) lesions., High flow lesions are clinically important as they are usually associated with congestive heart failure, embolism, bleeding $\&$ ulceration, clinically; they are firm on palpation. Low-flow lesions are usually soft $\&$ compressible on palpation like noticed in our case. HLA are noticed to be associated with various syndromes like RenduOsler-Weber syndrome, Sturge-Weber-Dimitri syndrome, Blue rubber bleb nevus syndrome, Parkes-Weber syndrome, Banayan's syndrome, Sturge-Weber-Krabbe syndrome, Klippel Trenaunay syndrome, Servelle-Martorell syndrome, Maffucci's syndrome and von Hippel-Lindau syndrome. ${ }^{5,6}$ They have intra-cranial extension thus CT scan helps to rule out syndromic aspect when other clinical features are ruled out.

The diagnosis of the type of vascular lesion is very important as it influences the management considerably. Angiographic studies only help in knowing the size, extent of lesion \& feeder vessels. ${ }^{3}$ These techniques usually have higher morbidity as compared to CT/MRI.
$\mathrm{CT}$ do help us in giving broad outline of lesion along with its extension along with bony margins. As this is minimally invasive technique we preferred for evaluation of the lesion. Immuno-histopathology also helps in detecting the lesion, which detects positive CD31 and D240 reactivity. New markers like Prox-1 and VEGFR3 are also used for detecting aberrant lymphatic vessels using antibodies which have been reported in literature. ${ }^{7}$

In literature, few cases have been reported of HLA/LHA of oral cavity. Histopathological evaluation is very important for vascular lesions to come for final diagnosis. Hemangioma histo-pathologically, shows densely cellular proliferation of endothelial cells in the early stages to a lobular mass of well-formed capillaries in the mature phase. In some cases, intermingled lymphatic channels are also evident. Diagnosis is given according to predominant components present in particular lesion. ${ }^{7}$ In our case, large number of engorged blood vessels with foci of chronic inflammatory cell infiltrate chiefly of lymphocytes were seen, thus diagnosed as HLA. In the table below, we have enumerated all cases reported as of now in literature (Table $1)$.

Table I Enumerated all cases reports

\begin{tabular}{|c|c|c|c|c|c|}
\hline Serial Number & Author & Year of publication & Age/Sex & Site & Diagnosis \\
\hline I & Vilalta J et al. ${ }^{8}$ & 1985 & $7 y / M$ & Dorsum of Tongue (Right Side) & Hemangio-Lymphangioma \\
\hline 2 & Seong Soo ${ }^{9}$ & 2003 & $62 y / M$ & Body Mandible (Left Side) & Hemangio-Lymphangioma \\
\hline 3 & Jian et al. ${ }^{10}$ & 2005 & $\begin{array}{l}3 \text { Patients } \\
\text { (1992-2002) }\end{array}$ & Tongue & Lymphangio-Hemangioma \\
\hline 4 & Shetty D et al." & 2009 & $5 y / F$ & Dorsum of Tongue (Right Side) & Hemangio-Lymphangioma \\
\hline 5 & Shetty et al. ${ }^{12}$ & 2010 & $9 y / F$ & Tongue Dorsum (Left Side) & Hemangio-Lymphangioma \\
\hline 6 & Sobhana et al. ${ }^{13}$ & 2012 & $18 y / M$ & Mucosa of Lip (Left Side) & Hemangio-Lymphangioma \\
\hline 7 & Deques $C$ et al. ${ }^{4}$ & 2013 & $6 y / M$ & $\begin{array}{l}\text { Neck, Floor of Mouth, Tongue } \\
\text { (Right Side) }\end{array}$ & Hemangio-Lymphangioma \\
\hline 8 & Hunchairsi $\mathrm{N}^{14}$ & 2013 & $4 \mathrm{ly} / \mathrm{F}$ & Floor of Mouth & $\begin{array}{l}\text { Hemangio-Lymphangioma } \\
\text { (Intra-Muscular) }\end{array}$ \\
\hline 9 & YarmandF et al..$^{15}$ & 2016 & $26 y / M$ & Buccal Mcosa (Left Side) & Lymphangio-Haemangioma \\
\hline 10 & Elviera $\mathrm{R}^{2}$ & 2016 & $6 y / F$ & Upper Lip & Hemangio-Lymphangioma \\
\hline 11 & $\begin{array}{l}\text { Bassem Abou } \\
\text { Merhi et al. }{ }^{16}\end{array}$ & 2016 & $2 y / M$ & Dorsum Of Tongue & Hemangio-Lymphangioma \\
\hline 12 & Manickem S et al. ${ }^{7}$ & 2017 & $21 y / F$ & Buccal Mucosa (Left Side) & Hemangio-Lymphangioma \\
\hline 13 & Reibero G ${ }^{17}$ & 2018 & $44 y / M$ & Tongue Dorsum & Hemangio-Lymphangioma \\
\hline 14 & Elitsa $D^{18}$ & 2019 & $46 y / F$ & Mandible & Hemangio-Lymphangioma \\
\hline
\end{tabular}

Management of these vascular malformations are usually done by Laser therapy, Embolization followed by Surgical excision. ${ }^{19}$ Surgical Excision of the lesion is the mainstay management of any vascular Malformations to minimise the risk of recurrences after delineation of margins with adequate radiological investigations as discussed above. Treatment options are primarily dependant on anatomical site and depth of lesion. Low-flow lesions can be successfully treated by interstitial laser therapy with more than one session for complete involution of lesion. Embolization helps in high flow lesions which aims to occlude the nidus of the malformation. ${ }^{4,20}$
Various other treatment modalities have also been advocated in literature, in areas where lesions are not amenable to surgery (due to access/ anatomic location/close approximate to vital structures) like intralesional injection of fibrosing agents, interferon $\mathrm{a}-2 \mathrm{~b}$, radiation, electrocoagulation and cryosurgery. ${ }^{20}$

Bogdan et al. ${ }^{21}$ did a study to evaluate the efficacy of the 980 $\mathrm{nm}$ diode laser and Er:YAG laser for photocoagulation of vascular lesions. Seventy consecutive patients with either hemangioma/ low-flow vascular malformations of the head and neck treated 
with laser photocoagulation were included in the study. Long-term follow-up recorded regression of the lesion in all patients with good aesthetic results with reduction in size between $45 \%$ and $95 \%$ and no complications/ reperfusion of the lesions was noted. They concluded that when properly applied, these techniques can achieve reduction in size of these lesions without compromising function and cosmetics. Technique seems like effective treatment for correctly selected patients.

Plasma knife (PK) is a new treatment modality for excision of these lesions. PK technology provides an electrically conducting site by means of obtaining the use of controlled radiofrequency energy, and by using the intra and extracellular fluid. The active zone on the device provides an ionized layer by means of radiofrequency waves. Dense kinetic energy divides, demolishes and evaporates the constructional element tissue. During this procedure, there is very little thermal damage to the surrounding tissue. Because it requires no additional saline supply for the operation according to the thermal procedure, its tip temperature remains cool at $70-80^{\circ} \mathrm{C}$ thus providing a pink viable resection bed. They have used \& reported a $90 \%$ coagulation and $10 \%$ cut mode choice for the PK excision of the haemangioma of the tongue. Thus, this could be considered as one of the viable option for superficial lesions or as an adjunctive while doing major resection of lesions. ${ }^{22-27}$

\section{Conclusion}

As we summarize, HLA/LHA is rare in the oral cavity particularly in buccal Mucosa. However, they should be always considered as differential diagnosis of swellings of oral cavity during examination of lesions. Accurate diagnosis is imperative for appropriate management of lesion. Based on their ability to invasion of HLA leading to bodily distortion, long term follow-up is recommended to rule out recurrences. To conclude, any vascular lesion in the oral cavity must be thoroughly evaluated with vigilance to prevent untoward incidences.

\section{Funding}

None.

\section{Acknowledgments}

None.

\section{Conflicts of interest}

The authors declare that there is no conflict of interest.

\section{References}

1. Mulliken JB, Glowacki J. Hemangiomas And Vascular Malformations In Infants And Children: A Classification Based On Endothelia Characteristics. PlastReconstr Surg. 1982;693:412-22.

2. Rozza-De-Menezes, Adriele Ferreira Gouvêa, AdemarTakahama, et al A Rare Case of Oral Haemangioma. Oral and Maxillofacial Pathology. 123(2).

3. Fishman SJ, Mulliken JB. Hemangiomas and vascular malformations of infancy and childhood. Pediatr Clin North Am. 1993;40(6):1177-1200.

4. Carlos S Duque, Andres FL, Adriana MP, et al. Hypoglossal Nerve Monitoring, A Potential Application of Intraoperative Nerve Monitoring In Head And Neck Surgery. World Journal of Surgical Oncology. 2013;11:225.
5. Greinwald JH, Burke DK, Bonthius DJ. An update on the treatment of hemangiomas in children with interferon $\alpha-2 \mathrm{a}$. Arch Otolaryngol Head Neck Surg. 1999;125(1):21-27.

6. Donnelly LF, Adams DM, Bisset GS. Vascular malformations and hemangiomas: a practical approach in a multidisciplinary clinic. Am $J$ Roentgenol. 2000;174(3):597-608.

7. Selvamani M, Prem S, B Nandakishore, et al. Hemangiolymphangioma of Buccal Mucosa: A Rare Case Report. J Oral Maxillofac Pathology. 2017;21(2):282-285.

8. Vilalta J, JM. Mascaro, Haemangiolymphangioma of tongue treated by transfixion technique, J DermatolSurgery Oncol. 1985.

9. Seong Soo K. Intraosseous Haemangiolymphangioma Of the Mandible: A Case Report. J Korean Assoc Oral Maxillo Surgeons. 2003;29(3):182185.

10. Jian XC. Surgical management of lymphangiomatous or lymphangio hemangio matousmacroglossia. JOral Maxillofac Surg. 2005;63(1):1519.

11. Shetty D, H Rai, P Rastogi, et al. Vascular Malformations Of The Oral Cavity In Children And Young Adolescents - Insights Into Their Pathogenesis.The Internet Journal of Pediatrics And Neonatology. 2009;12(2).

12. Shetty DC, Urs AB, Rai HC, et al. Case Series On Vascular Malformation And Their Review With Regard To Terminology And Categorization. ContempClin Dent. 2010;1(4):259-262.

13. Sobhana CR, Beena VT, Soni A, et al. Hemangiolymphangioama of Buccal Mucosa: Report of A Rare Case And Review of Literature on Treatment Aspect. Natl J Maxillofac Surg. 2012;3(2):190-194.

14. Hunchaisri N. Hemangiolymphangioma of the floor of mouth: a case report and literature review. J Med Health Sci. 2013;20:4-9.

15. Yarmand F, Seyyedmajidi M, Shirzad A, et al. Lymphangio hemangioma Of Buccal Mucosa: Report of A Rare Case. J Oral Maxillofacsurg Med Pathol. 2016;28:358-361.

16. BassemAbouMerhi, Amal Nous MD, Mariam Rajab, et al. Haemangiolymphangioma of tongue, Report of a rare case.EJBPS. 2016;3(5):88-91.

17. Gabriela Alves Ribeiro, Ana Maria Rocha Dias, Ana FláviaSchueler De AssumpçãoLeite, et al. Oral Hemangiolymphangioma: A Case Report. Oral and Maxillofacial Pathology. 2018;126(3):E71.

18. ElitsaDeliverska. Hemangiolymphangioma of the Mandible. Case Report J of Imab. 2019;25(4):2729-2732.

19. Rajendran R, Sivapathasundharam B. Shafer's Text Book of Oral Pathology. 5th ed. Gurgaon, Haryana: Elsevier, A Division of Reed Elsevier India Private Limited, 2006;197.

20. Kulkarni CV, Parul N, Harshul P, et al. Hemangiolymphangioma of Neck - A Rare Case With Review Report JMSCR. 2014;2:1869-1872.

21. Bogdan VC, Mihaela B, Grigore B, et al. Laser treatment in oral and maxillofacial hemangioma and vascular malformations. TMJ. 2010;60(1):34-38.

22. Tyler Murphy, Daryl Ramai, Jonathan Lai, et al. Adult Neck Hemangiolymphangioma: A Case And Review Of Its Etiology, Diagnosis And Management. Journal of Surgical Case Reports. 2017;8:1-5.

23. Castro EC, Galambos C. Prox-1. and VEGFR3 antibodies are superior to D2-40 in identifying endothelial cells of lymphatic malformations - a proposal of a new immunohistochemical panel to differentiate lymphatic from other vascular malformations. Pediatr Dev Pathol. 2009;12(3):187194. 
24. Richter GT, Friedman AB. Hemangiomas and vascular malformations: current theory and management. Int J Pediatr. 2012;2012:645678.

25. Werner JA, Dunne AA, Folz BJ, et al. Current concepts in the classification, diagnosis and treatment of hemangiomas and vascular malformations of the head and neck. Eur Arch Otorhinolaryngol. 2001;258(3):141-149.
26. van Doorne L, De Maeseneer M, Stricker C, et al. Diagnosis and treatment of vascular lesions of the lip. Br J Oral Maxillofac Surg. 2002;40:497503.

27. Kutluhan A, Bozdemir K, Ugras S. The treatment of tongue haemangioma by plasma knife surgery. Singapore Med J. 2008;49(11):e312-14. 